\title{
Contributors to the frequency of intense climate disasters in Asia-Pacific countries
}

\author{
Vinod Thomas • Jose Ramon G. Albert • \\ Cameron Hepburn
}

Received: 13 September 2013 / Accepted: 17 August 2014 / Published online: 29 August 2014

C) The Author(s) 2014. This article is published with open access at Springerlink.com

\begin{abstract}
The frequency of intense natural disasters (defined here as events triggered by hazards of nature and causing at least 100 deaths or affecting the survival needs of at least 1,000 people) has been on the rise over the past 40 years. This is especially true for Asia and the Pacific, where such disasters have long been relatively frequent. A crucial question is the extent to which the frequency of such disasters is related to increases in the number of people exposed to hazards, changes in people's vulnerability to hazards, and temperature and precipitation anomalies. This paper addresses this question with an econometric analysis of disaster risk determination for countries of Asia and the Pacific during 1971-2010. The objective is to determine the role (if any) of greater likelihood of climate-related natural hazards, alongside changes in exposure of people to the hazards and their greater vulnerability, in explaining the annual frequency of climate-related disasters. Results indicate that hydrometeorological disasters are strongly associated with rising population exposure as well as precipitation anomalies, while climatological disasters are strongly associated with changing temperatures. Taken together with the evidence from literature that it is "very likely" that the rising incidence of greenhouse gas emissions in the atmosphere is altering the climate system, the findings suggest a connection between the frequency of intense natural disasters observed in the region and man-made climate change.
\end{abstract}

\footnotetext{
V. Thomas $(\bowtie)$

Asian Development Bank, 6 ADB Avenue, Mandaluyong 1550, Philippines

e-mail: vthomas@adb.org

J. R. G. Albert

Philippine Institute for Development Studies, 106 Amorsolo Street, Legaspi Village, 1229 Makati, Philippines

e-mail: jalbert@mail.pids.gov.ph

C. Hepburn

Smith School of Enterprise and the Environment, Oxford University Centre for the Environment, South Parks Road, Oxford OX1 3QY, United Kingdom

e-mail: cameron.hepburn@smithschool.ox.ac.uk
} 


\section{Introduction}

The frequency of intense natural disasters (defined here as events triggered by hazards of nature and causing at least 100 deaths or affecting the survival needs of at least 1,000 people) ${ }^{1}$ increased notably from the 1970s to the 2000s. Intense hydrometeorological disasters (related to floods and storms), and climatological disasters (related to droughts and heat waves) to a lesser extent, accounted for most of the worldwide increase in natural disasters (Fig. 1). Around half of these occurred in Asia and the Pacific ("Asia-Pacific" from here on); nearly three-fourths of these were intense hydro-meteorological disasters.

While improved reporting is sometimes credited with some of such rising frequencies, our focus on intense events (which are less likely to be under-reported in the past) reduces that possibility (Peduzzi et al. 2009; Thomas et al. 2013). Furthermore, while we note a sizable increase in the frequency of intense climate-related ${ }^{2}$ disasters, the frequency of intense geophysical disasters (related to earthquakes and volcanoes) has only slightly increased.

Figure 2 sets out three linkages involving climate-related disasters. First, greenhouse gas (GHG) emissions alter atmospheric GHG concentrations and thus affect climate variables, specifically temperature and precipitation (IPCC 2007). Second, changes in the climate variables affect the frequency of climate-related hazards (IPCC 2012). Third, the frequency of climate-related hazards affects the risk of natural disasters (IPCC 2012; Stott et al. 2012). We define disaster risk as the likelihood of losses (deaths, injuries, destruction and damage to property, and others) that a hazard might cause. Disaster risk is influenced by three elements: (i) the hazard itself; (ii) the population exposed to the hazard (exposure); and (iii) the community's ability to withstand its impact (vulnerability) (Peduzzi et al. 2009; Thomas et al. 2013). Population exposure and vulnerability together can turn a specific natural hazard into a disaster.

There is a great deal of research on the science of climate change (IPCC 2013; IPCC 2012; Hansen and Sato 2012; Huber and Knutti 2012; Knutson et al. 2010; and Trenberth 2011), as well as a growing and somewhat controversial literature on natural disasters and climate change (IPCC 2012 and 2013; Mendelsohn et al. 2012; Bouwer 2011; Kunkel et al. 2013; Pielke et al. 2008; Li et al. 2013; Hallegatte 2012; Coumou and Rahmsdorf 2012). ${ }^{3}$ Different studies bring out the link between GHG emissions and climate change as well as climate related hazards. Some of the literature, on the other hand, suggests that anthropogenic climate change does not have an impact on the losses from natural disasters. This paper contributes to the literature through an econometric analysis, a set of statistical methods commonly used in analyzing socioeconomic variables to test a hypothesis. This allows us to examine the importance of three principal factors, exposure, vulnerability and climate change, taken together, in the rising threat of natural disasters in Asia-Pacific.

Kellenberg and Mobarak (2008) and Kahn (2005) examined the role of exposure and vulnerability as determinants of the frequency of death toll from natural disasters, employing negative binomial regressions over annual country observations (panel data) worldwide for the

\footnotetext{
${ }^{1}$ Reported events causing at least 10 deaths, affecting at least 100 people, or prompting a declaration of a state of emergency or a call for international assistance are recorded in the International Disaster Database (EM-DAT). Of these recorded disasters, this paper considers intense events, defined here as those causing at least 100 deaths or affecting the survival needs of at least 1,000 people.

${ }^{2}$ Most climate-related disasters are rapid onset disasters (e.g. disasters related to cyclones, hurricanes and typhoons). In the case of floods, while some arrive very fast, others arrive within specific season or with a few days warning and are slow onset. Droughts are relatively slow onset disasters that can occur over a long period of time.

${ }^{3}$ For a more detailed discussion of related literature, see Thomas et al. (2013).
} 


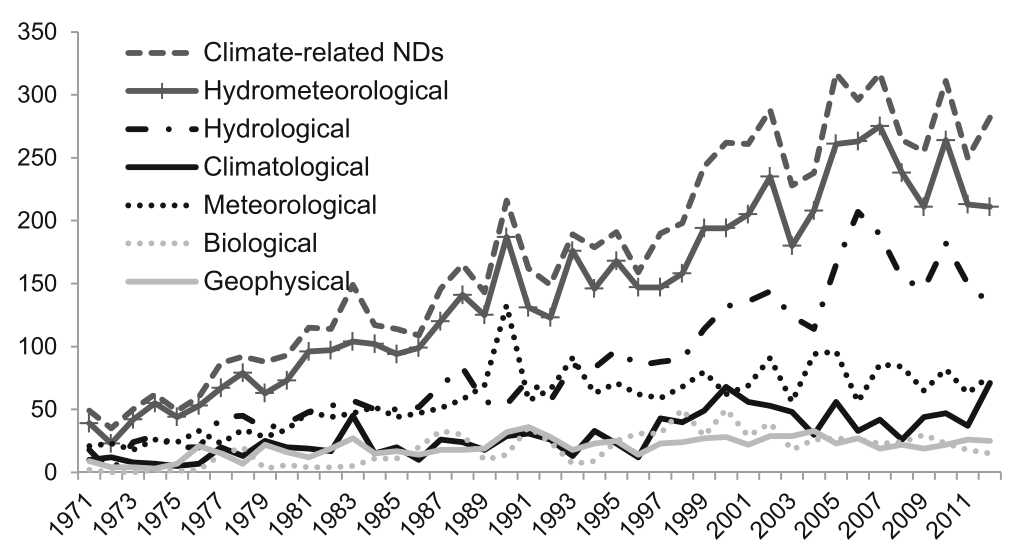

Fig. 1 Global frequency of intense natural disasters by type (1971-2012)

periods 1975-2002 and 1980-2002. Other econometric analyses (Rentschler 2013; Bakkensen 2013; Noy 2009; Skidmore and Toya 2002) considered the determinants of disaster cost. Our study builds on existing econometric models that analyze hypothesized contributors to a phenomenon, in this case, natural disasters. As in many of these models, it assesses the significance of the key factors contributing to the frequency of intense natural disasters over time and across countries. One main difference from previous work is our use of climate anomalies as independent variables, in addition to exposure and vulnerability. We employ the frequency of intense natural disasters as the dependent variable because it is less likely to have a measurement bias compared to the alternative of using value of losses or damages due to disasters.

\section{Methods and Data}

It is very difficult to establish causal relations among the variables in our analysis. But following Kellenberg and Mobarak (2008) and Kahn (2005), we use econometrics to test the association between the frequencies of intense disasters due to floods and storms, as well as those due to droughts and heat waves, and the three identified factors of disaster risk.

The dependent variables in the analysis are the annual frequencies of hydrometeorological $^{4}\left(H_{\mathrm{it}}\right)$ and climatological ${ }^{5}$ disasters $\left(C_{\mathrm{it}}\right)$ that killed 100 or more people or affected 1,000 or more in country $i$ in year $t$. Data for these variables are obtained from EM-DAT (2011). ${ }^{6}$ Other research defines disaster risk as the probable level of damages in US dollars, based on historical data. However, measuring the impact of natural disaster in monetary terms is constrained by the lack of standards for comparable estimation across countries.

As both dependent variables are count variables, two econometric count models are used. The Poisson model, which assumes that the count dependent variable has a

\footnotetext{
${ }^{4}$ EM-DAT defines hydrological disasters as "events which are caused by deviations in the normal water cycle and/or overflow of bodies of water caused by wind set-up," and meteorological disasters are those "caused by short-lived/small to mesoscale atmospheric processes (in the spectrum from minutes to days)."

${ }^{5}$ Climatological disasters in EM-DAT refer to "events caused by longlived/meso- to macro-scale processes."

${ }^{6}$ A summary of the descriptive statistics for the variables used in the regressions is provided in Appendix Table 5.
} 


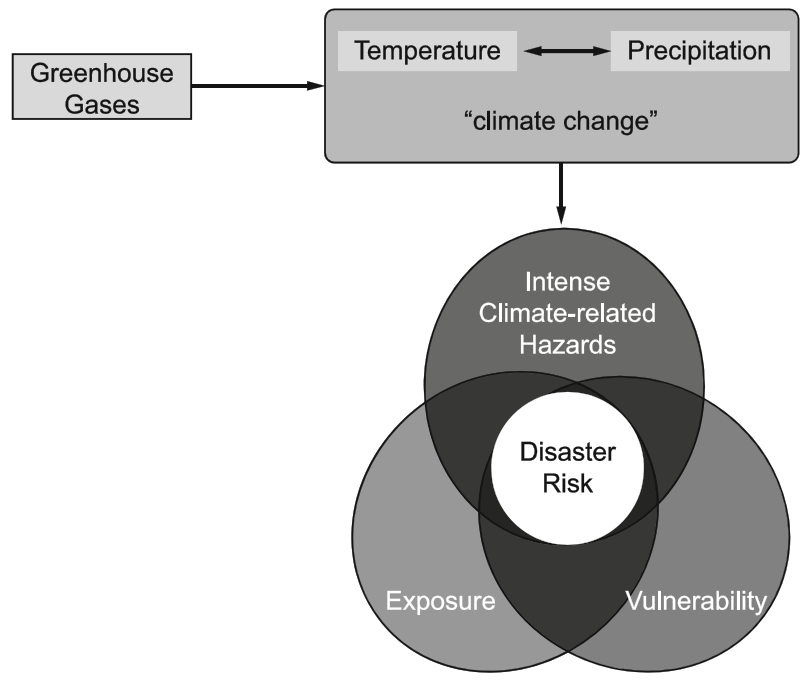

Fig. 2 Greenhouse gases, climate, and disaster risk

Poisson distribution, is employed for climatological disasters because it satisfies the necessary equidispersion assumption (i.e., the mean of the frequency of climatological disasters is equal to its variance). Meanwhile the negative binomial regression model ${ }^{7}$ (Allison and Waterman 2002) is employed for hydrometeorological disasters as likelihood ratio tests indicate over-dispersion (i.e., the variance of the frequency of hydrometeorological disasters is greater than its mean). Specifically, we estimate the following regression equations using annual observations for each of the 53 AsiaPacific countries ${ }^{8}$ (panel data) over 1971-2010, both with country fixed and random effects. ${ }^{9}$ The term "panel data" refers to observations of the same entities such as people, firms or countries over different points in time. Regression equations based on such data, or panel regressions, allow for the estimation of a relationship between dependent and independent variables while controlling for time-invariant country specific factors and/or variables that change over time but not across countries. ${ }^{10}$

$$
\begin{gathered}
E\left[H_{i t} \mid U_{i t}, V_{i t}, W_{i t}, X_{i t}\right]=\exp \left(\beta_{0}+\beta_{1} U_{i t}+\beta_{2} V_{i t}+\beta_{3} W_{i t}+\beta_{4} X_{i t}\right) \exp \left(\varepsilon_{i t}\right) . \\
E\left[C_{i t} \mid U_{i t}, V_{i t}, W_{i t}, X_{i t}, Z_{i t}\right]=\exp \left(\beta_{0}+\beta_{1} U_{i t}+\beta_{2} V_{i t}+\beta_{3} W_{i t}+\beta_{4} X_{i t}+\beta_{5} Z_{i t}\right)
\end{gathered}
$$

\footnotetext{
${ }^{7}$ The negative binomial regression model is an econometric model for count variables with over-dispersion. It is derived from the Poisson model by adding an independently distributed error term $(\varepsilon)$. It allows the mean to differ from the variance of the count variable such that variability of $Y$ is assumed to be equal to the mean: $\operatorname{Var}(Y \mid X)$ $=E(Y \mid X)[1+\alpha E(Y \mid X)]$ where $E(Y \mid X)=\exp \left(\beta_{0}+\beta_{1} X_{1}+\beta_{2} X_{2}+\cdots+\beta_{k} X_{k}\right)$ and $\alpha$ is a measure of dispersion. When $\alpha$ is not significantly greater from zero (i.e., no overdispersion), the negative binomial model reduces to the Poisson model. The negative binomial regression model is more efficient when $\alpha$ is significantly different from zero (i.e., the count outcome data are over dispersed).

${ }^{8}$ See Appendix Table 6 for a list of countries in our sample.

${ }^{9}$ In panel data analysis, while the random effects model assumes that individual (e.g. country) specific factors are uncorrelated with the independent variables, the fixed effects model recognizes that the individual specific factors are correlated with the independent variables.

${ }^{10}$ See Baltagi (2008)
} 
Population exposure $\left(\mathrm{U}_{\mathrm{it}}\right)$ is measured here by the logarithm of population density (people per square kilometer) in the country, as a proxy for the actual population exposed to a hazard (Birkmann 2007; Taubenböck et al. 2008). We use national-level data for all variables given their availability for all (socio-economic and climatic) variables, and given the advantages of consistency across all variables. We recognize that the use of national-level data can hide intracountry information, for example, on the distribution of the population within the country such as the rise or presence of densely populated coastal areas. Further research could seek to collect and analyze data on relevant variables at an intra-country level.

The regression also includes total population per country $\left(X_{i t}\right)$ as a control variable to reflect the possibility that the frequency of natural disasters surpassing the intense reporting threshold would be higher when the overall population increases.

Socioeconomic vulnerability ( $\left.V_{i t}\right)$, or the population's capability to cope with a hazard, is represented here by the natural logarithm of real income per capita. Vulnerability, a multidimensional concept, ${ }^{11}$ is a function of wealth and other demographic and socioeconomic factors (Füssel and Klein 2006). In this paper, we focus on socioeconomic vulnerability which is often proxied by income levels. Previous research has shown vulnerability to be positively associated with disaster risk (Kahn 2005; Noy 2009; Toya and Skidmore 2007). The square of the natural logarithm of real income per capita is included to capture a hypothesized nonlinear, inverted-U relationship between natural disasters and average income which is posited to emerge as the result of two different effects (Kahn 2005; Kellenberg and Mobarak 2008). First, as income increases from very low levels, individuals may rationally choose to take advantage of new economic opportunities that involve bearing more disaster risk. However, as income grows further and the marginal utility of further consumption falls, the risk-return trade-off moves to favor reduction of disaster risk.

For the water-related and temperature-related climate hazards, we employ annual data on average precipitation anomaly $\left(W_{i t}\right)$ and average surface temperature anomaly $\left(Z_{i t}\right)$. These are based on quality-controlled monthly data from the Global Precipitation Climatology Center (GPCC 2011) and the Met Office Hadley Centre and the Climate Research Unit ${ }^{12}$ (CRU) at the University of East Anglia (Morice et al. 2012). ${ }^{13}$ Both the GPCC's precipitation anomaly and CRU's temperature anomaly are computed as departures from the average for its 30-year base climatology period-1961-1990 (the period with the best data coverage).$^{14}$ Climate anomalies more accurately describe how climate varies over larger areas, as well as how it trends over

\footnotetext{
${ }^{11}$ Aside from economic, social, cultural, environmental, and psychological dimensions, some studies also consider physical and ecological dimensions of vulnerability (e.g. McDowell et al. 2013; Hutanuwatr 2012; Hinkel 2011; Luers 2005). Here, these are captured by the exposure variable in this paper. While the various dimensions of vulnerability can be contextual, there are also common elements across time, space, and scale (see Kelly and Adger 2000, Turner II et al. 2003, Thomalla et al. 2006, Füssel and Klein 2006, Smith and Wandel 2006, O’Brien et al. 2007, and Internal Disaster Monitoring Centre 2009). For a detailed literature on social vulnerability, see Cutter et al. (2009).

${ }^{12}$ CRU's HADCRUT3 temperature anomaly dataset is available on a spatial resolution of $2.5^{\circ} \times 2.5^{\circ}$ (latitude by longitude) grid across land and ocean surfaces.

${ }^{13}$ Based on quality-controlled data from 67,200 stations world-wide, GPCC's full precipitation dataset is available on a high spatial resolution (latitude by longitude: $2.5^{\circ} \times 2.5^{\circ}$ global grid). Other longitudinal global precipitation datasets are based on data from less number of stations and available on a lower spatial resolution only. For instance, the Global Historical Climatology Network (GHCN) precipitation dataset which has recent global data up to 2012 is based only on 20,590 stations worldwide and is available on a $5^{\circ} \times 5^{\circ}$ resolution only. ${ }^{14}$ Different climate anomaly datasets use different base climatology periods. For instance, GHCN uses 19712000 as its base climatology period for its precipitation anomaly datasets. It is important to note that overall, adjustment of data to different reference periods does not change the shape of climate anomaly time-series or affect the trends within it.
} 
time, and allow more meaningful comparisons between locations (with varying elevations) than absolute climate indicators.

Average climate anomaly by country and year are computed as mean anomalies of all grid squares lying within a bounding box containing the country defined by the maximum and minimum latitude and longitude. ${ }^{15}$ Grid level climate anomaly data are available from the Food and Agriculture Office of the United Nations.

In representing climate as an independent variable, equation (1) relies on precipitation anomaly, which is, in turn, influenced by the temperature anomaly. Equation (2) includes temperature anomaly as an additional independent variable reflecting the observation that temperature is more directly related to climatological disasters than hydrometeorological disasters.

We also consider whether the climate anomaly coefficients vary over five subregions of Asia-Pacific, specifically Southeast Asia, East Asia, South Asia, Central Asia and the Pacific (see Fig. 3). ${ }^{16}$ We consider this because precipitation is even more spatially variable than temperature (Rudolf et al. 2010). According to the 2012 Intergovernmental Panel on Climate Change (IPCC) Report "it was likely that there had been increases in the frequency of heavy precipitation events (e.g., 95th percentile) over the second half of the 20th century within many land regions... There is low to medium confidence in trends in heavy precipitation in Asia... However, statistically significant positive and negative trends were observed at subregional scales within these regions..."

This paper uses an unconditional fixed effects negative binomial panel regression model (all parameters estimated) rather than a conditional fixed effects panel regression model (or conditional on the value of a sufficient statistic for one or more parameters). The latter would not be a true fixed effects model, because it does not control for unchanging covariates or the variables that are possibly predictive of the outcome under study (Allison and Waterman 2002).

Since changes in climate typically persist for decades or longer (IPCC 2012), we also look at disaster frequencies on a decadal basis. To capture the effect of the frequency of climate anomalies, we estimate equations (1) and (2) using decadal observations for each Asia-Pacific country in the sample over four decades: 1971-1980, 1981-1990, 1991-2000, 2001-2010. We also consider the number of years with positive average precipitation (temperature) anomaly as an additional explanatory variable.

The panel regressions employed here have limitations. The panel data used in the regressions are somewhat unbalanced, because data for climate and vulnerability indicators are not available for some years in some countries for the period under study (see Appendix Table 6 for number of sample observations and period by country). Also, population exposure and vulnerability may not be fully exogenous. If the regressors are not strongly exogenous, then the coefficient estimates will be inconsistent and thus cannot be relied upon to compute marginal effects. Nonetheless, while the frequency of disasters may affect the population exposed to disasters and their income, its direct effect on the exposure and vulnerability indicators in this paper is expected to be limited.

The period covered in the analysis was limited by the availability of quality-controlled global precipitation data. ${ }^{17}$ The choice of variables used in the model is constrained by data

\footnotetext{
${ }^{15}$ The average climate anomaly in country $i$ and year $t$ is computed as follows: $X_{i t}=\sum \sum^{\max (j, k)} x_{i m} /(\#$ of grids) where $x_{i m}$ is the average climate anomaly for country $i$ and month $m$, $(j, k)$ represents $(7)$ maink $k$; $k$ spatial grid.

${ }^{16}$ This is implemented empirically by the use of an interaction variable, which is the product of average climate anomaly and a dummy variable that takes a value 1 if the country belongs to a subregion and 0 otherwise.

${ }^{17}$ GPCC's full precipitation dataset is updated up to 2010 only. Other alternative longitudinal global precipitation datasets are based on data from fewer stations and available on a lower spatial resolution only.
} 


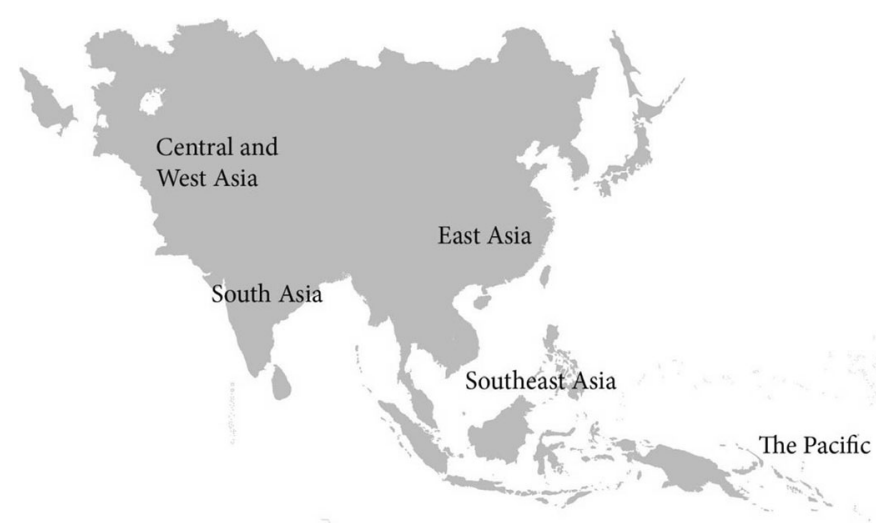

Fig. 3 Map of Asia and the Pacific and its subregions

availability. For example, variables such as land use (Brath et al. 2006), the actual number of people living in the hazard-prone areas, and the share of these figures to the total population would have been of keen interest. However, these data are neither regularly generated nor readily available. Furthermore, our analysis is based on the annual picture because data for some of the control variables, such as population density and population, are only available annually.

\section{Results}

Table 1 shows the results of our negative binomial model with random (columns 1 and 2) and country-fixed effects (columns 3 and 4), unpacking the drivers of disasters due to floods and storms in Asia-Pacific in the past four decades, using annual country-level data. Results of generalized Hausman specification tests (Hausman and Taylor 1981), as well as the strongly significant estimates for most country indicator variables, support the use of country fixedeffects (equation 1; also see results in columns 3 and 4 in Table 1), instead of random effects (equation 2; columns 1 and 2 in Table 1). These results confirm that country-specific factorspossibly ones such as governance effectiveness and quality of institutions (Tol and Yohe 2007; Brooks et al. 2005; Barr et al. 2010) - may contribute to the frequency of intense climaterelated disasters in Asia-Pacific. Their effect might also be viewed as interaction effects of exposure and vulnerability.

We find a statistically significant relation between the annual frequency of these disasters and two of the three drivers - population exposure and climate hazards. The relationship between their annual frequencies and the vulnerability variable in this model does not show statistical significance.

Exposure, proxied by population density, is a strong significant driver, both statistically and economically. Specifically, a $1 \%$ increase in the number of people per square kilometer is associated with a $1.2 \%$ increase in the average annual frequency of intense hydrometeorological disasters in a country (see columns 3 and 4 in Table 1). All else equal, countries that are more densely populated are significantly more likely to suffer an intense disaster when a storm or flood hits.

When vulnerability is represented by average income level, the coefficients on the level and square of income suggest first a positive association between income and annual frequency of 
Table 1 Intense hydrometeorological disasters in Asia and the Pacific

Dependent variable: Intense hydrometeorological disasters (1971-2010)

Explanatory variables Random effects

(1)

Exposure

Ln(population density)

0.2366

[0.148]

0.2409

[0.149]

$1.1928 * * *$

[0.255]

Vulnerability

Ln(GDP per capita, constant 2000 \$)

0.9213

[1.460]

0.9525

[1.462]

1.9222

[1.242]

Square of Ln(GDP per capita, constant 2000 \$)

$-0.0758$

$-0.0776$

$-0.1101$

[0.100]

[0.100]

[0.086]

Climate hazard

Average precipitation deviation

Average precipitation deviation $\mathrm{x}$ East Asia

Average precipitation deviation $\mathrm{x}$ South Asia

Average precipitation deviation x Central Asia

Average precipitation deviation $\mathrm{x}$ Pacific

Population (in million)

Observations

Number of economies

Pseudo R-squared

Alpha

LR test of alpha $=0$ (Chi-bar, $\bar{\chi})$

\begin{tabular}{llll}
$0.0111^{* * *}$ & $0.0114^{* * *}$ & $0.0062^{* * *}$ & $0.0037^{* * *}$ \\
{$[0.002]$} & {$[0.002]$} & {$[0.002]$} & {$[0.001]$} \\
& $-0.0086^{* *}$ & & $0.0074^{* * *}$ \\
& {$[0.004]$} & & {$[0.002]$} \\
& 0.0054 & & $0.0127 * * *$ \\
& {$[0.004]$} & & {$[0.002]$} \\
& $0.0497^{* * *}$ & & $0.0995^{* * *}$ \\
& {$[0.016]$} & & {$[0.026]$} \\
& -0.0021 & & -0.0014 \\
$0.0023 * * *$ & $0.0023 * * *$ & -0.0002 & {$[0.005]$} \\
{$[0.001]$} & {$[0.001]$} & {$[0.001]$} & -0.0003 \\
1,685 & 1,685 & 1,685 & {$[0.001]$} \\
53 & 53 & 53 & 1,685 \\
0.099 & 0.100 & 0.369 & 0.372 \\
1.631 & 1.622 & 0.049 & 0.046 \\
691.9 & 679.7 & 9.032 & 8.180 \\
\hline
\end{tabular}

*** significant at $1 \%$. Figures are negative binomial panel regression results. An intercept term and country dummies are included but not reported here. The coefficient of 'Average Precipitation Deviation" in specifications (2) and (4) represents the coefficient for Southeast Asia- the reference subregion (omitted dummy). Robust country-cluster z statistics in brackets

the disaster at lower levels of income and then a negative association at higher levels, but they are not statistically significant. When vulnerability is represented by a poverty indicator, (see Thomas et al. 2013), the coefficient estimates are not robust to changes in sample time periods (such as 1980-2010 or 1990-2010), or to the use of different threshold levels for poverty head count ratio (such as $25 \%$ or $35 \%$ ).

Average precipitation anomaly is a consistently significant factor in explaining the annual frequency of intense climate disasters. Holding other variables constant, a unit increase in the annual average precipitation anomaly from the 30-year average baseline rainfall (1960-1990) is associated with around a $0.6 \%$ increase in the annual frequency of disasters due to floods and storms. Temperature anomaly might also be considered a potential climate hazard variable 
with regard to meteorological disasters. Reflective of observations in IPCC (2012), ${ }^{18}$ however, we find a relationship between average temperature anomaly and the frequency of intense meteorological disasters that is very sensitive to model specification-random effects and country-fixed effects. The relationship between average precipitation anomaly and frequency of hydrometeorological disasters (as well as hydrological ones) remains positive and significant with and without the inclusion of the average temperature anomaly variable. It also remains positive and strongly significant when climate subregion interaction terms are used (columns 2 and 4 in Table 1).

The coefficient for average precipitation anomaly varies across subregions. For example, results in column 4 suggest that a unit increase in the annual average precipitation anomaly is associated with a $0.4 \%$ average increase in frequency of disasters due to floods and storms in Southeast Asia; $1.1 \%$ in East Asia (i.e., the sum of 0.0037 and 0.0074 ); $1.6 \%$ in South Asia; $10.3 \%$ in Central Asia; and $0.2 \%$ in the Pacific. ${ }^{19}$ Except for the Pacific, all the coefficient estimates for the interaction terms are significantly different from zero.

The coefficient estimate for average precipitation anomaly remains positive and strongly significant when a time trend variable is included to control for other factors that affect the frequency of intense disasters and that are not directly observable but are highly correlated with time (e.g., location of population). The coefficient of the time trend variable is significant and positive across specifications (not shown).

Table 2 illustrates what this might mean for some of the countries in question. Using the coefficient estimates for average precipitation in the specification with the highest pseudo R-squared (column 4 in Table 1), we estimate the increase in the frequency of these disasters from the 2001-2010 levels for Indonesia, the Philippines, and Thailand under three scenarios. We use the observed increase in average precipitation anomaly from 1991-2000 to 2001-2010 (8.33 $\mathrm{mm}[\mathrm{mm}]$ per month) among countries in Southeast Asia, including Brunei Darussalam, Indonesia, the Lao People's Democratic Republic, Malaysia, the Philippines, Singapore, Thailand, and Viet Nam, for setting the possible increase in the average precipitation anomaly under three scenarios: Scenario 1 (low increase) represents an increase in the average precipitation anomaly by $4 \mathrm{~mm}$ per month; Scenario 2 (moderate increase) by $8 \mathrm{~mm}$ per month; and Scenario 3 (high increase) by $12 \mathrm{~mm}$ per month.

The estimates suggest that, holding other things constant, an increase in average precipitation anomaly by $8 \mathrm{~mm}$ per month (moderate scenario), as experienced in Southeast Asia in the last decade, could be associated with an increase in the average frequency of disasters due to floods and storms in Indonesia by an average of around 0.18 per year from an average of 6 a year in 2001-2010. This is equivalent to an additional event in Indonesia every 5-6 years. In the Philippines the moderate scenario is associated with an increase of around 0.35 disaster a year, or an additional disaster every 3 years; in Thailand the increase is 0.11 disaster a year, or an additional disaster every 9 years. If the increase in average precipitation hits $12 \mathrm{~mm}$ per month (high scenario), greater increases in the frequency of these disasters can be expected: one additional event every 4 years in Indonesia, every 2 years in the Philippines, and every 6 years in Thailand. These assumptions were based on the observed increases in precipitation anomalies between the last two decades (1991-2000 and 2001-2010). This does not

\footnotetext{
${ }^{18}$ IPCC (2012) finds lower confidence with respect to increases for storms than floods, and a demonstrable link to climate more tenuous.

${ }^{19}$ Note that Central Asia has relatively few intense floods and storms, so a given increase in precipitation deviation in this otherwise relatively dry subregion implies a large percentage change in disasters, especially in view of its lack of preparedness.
} 
Table 2 Increase in intense hydrometeorological disasters associated with an increase in precipitation deviation

\begin{tabular}{|c|c|c|c|c|c|}
\hline Country & $\begin{array}{l}\text { Annual frequency of } \\
\text { hydro-meteorological di- } \\
\text { sasters }(2001-2010)\end{array}$ & $\begin{array}{l}\text { Precipitation deviation } \\
\text { (millimeters per } \\
\text { month, 2001-2010) }\end{array}$ & $\begin{array}{l}\text { Scenario 1: } \\
\text { Low increase } \\
(d W=4)\end{array}$ & $\begin{array}{l}\text { Scenario 2: } \\
\text { Moderate } \\
\text { increase }(d W= \\
8)\end{array}$ & $\begin{array}{l}\text { Scenario } 3 \text { : } \\
\text { High increase } \\
(d W=12)\end{array}$ \\
\hline
\end{tabular}

Increase in the annual frequency of intense hydrometeorological disasters associated with an increase in precipitation deviation $(d H=$ $\left.\beta_{3} * d W H_{o}\right)$

\begin{tabular}{llllll}
\hline Indonesia & 6.00 & 9.92 & 0.09 & 0.18 & 0.27 \\
Philippines & 11.80 & 10.84 & 0.18 & 0.35 & 0.53 \\
Thailand & 3.60 & 1.14 & 0.05 & 0.11 & 0.16 \\
\hline
\end{tabular}

Estimates are computed using the estimated coefficient of 'Average precipitation deviation' for the reference subregion (Southeast Asia) in Table 1 column (4), that is, $\beta_{3}=0.0037$

necessarily mean that precipitation levels would increase in the future. IPCC 2014 notes that precipitation trends vary across countries with both increasing and decreasing trends observed in different parts of Asia.

Table 3 shows a negative relationship between average precipitation anomaly and intense climatological disasters. It also shows a positive relationship between temperature anomaly and intense climatological disasters: disasters due to droughts and heat waves tend to occur when it is unusually dry and hot. IPCC 2012 finds "medium confidence" that droughts have become more intense and frequent, which together with the rising trends in precipitation and temperature anomalies, provides the context for the present findings.

A unit increase in average precipitation anomaly is associated with a $3 \%$ reduction in the annual frequency of disasters due to droughts and heat waves, while a unit increase in temperature anomaly is associated with a $72 \%$ increase in the annual frequency of disasters due to droughts and heat waves (see column 3 in Table 3). The coefficients of these two climate variables are significant with both random and country fixed-effects. However, the coefficients for the climate variables are not statistically significant when including climate subregion interaction terms. Except for Central Asia and the Pacific, there is no significant variation in the effect of average precipitation anomaly on climatological disasters across subregions. The coefficients of exposure and vulnerability variables also are not significant.

Table 4 confirms that population exposure and vulnerability, as well as of the frequency of climate anomalies, are significant in explaining decadal changes in the average annual frequency of intense disasters due to floods and storms. Specifically, changes in average annual income per capita are significant in explaining decadal changes in the average annual frequency of these disasters. Both the average precipitation anomaly and the number of years that the average precipitation anomaly was positive are significant. Similarly, average temperature anomaly and the frequency of positive temperature anomaly are both significant for explaining decadal increases in the annual average frequency of intense climatological disasters but not population density nor income. While Hausman specification tests justify the use of country-fixed effects, since the number of decadal observations per country is at most only four, we rely in this case on the results with random effects. 
This econometric analysis gives us a basis to explore further the role of the climate variables, in addition to socioeconomic variables in assessing disaster trends. The association between precipitation anomaly and disasters related to floods and storms features with a high degree of statistical significance.

Table 3 Intense climatological disasters in Asia and the Pacific

Dependent variable: Frequency of intense climatological disasters (1971-2010)

Explanatory variables

Exposure

Ln(population density)

Vulnerability

Ln(GDP per capita, constant 2000 \$)

Square of Ln(GDP per capita, constant 2000 \$)

Climate hazard

Average precipitation deviation

Average precipitation deviation $\mathrm{x}$ East Asia

Average precipitation deviation $\mathrm{x}$ South Asia

Average precipitation deviation x Central Asia

Average precipitation deviation $\mathrm{x}$ Pacific

Average temperature anomalies

Average temperature anomalies x East Asia

Average temperature anomalies x South Asia

Average temperature anomalies x Central Asia

Average temperature anomalies x Pacific

Population (million)

Observations

Pseudo R-squared
Random effects

(1)

(2)

$\begin{array}{lll}-0.0263 & -0.0901 & 1.1802 \\ {[0.222]} & {[0.212]} & {[0.861]}\end{array}$

$$
-1.1159
$$

$$
-1.3585
$$

0.0223

0.0599

0.0780

0.0138

[0.095]

[0.126]

$-0.0163 * * *$
$[0.006]$

$-0.0146$

[0.013]

0.0080

$-0.0267 * * *$

[0.009]

[0.017]

$-0.0208$

[0.024]

-0.0562 *

[0.033]

0.0033

[0.018]

$0.5505 * * *$

$1.2078^{* *}$

[0.204]

[0.459]

0.7241 **

[0.313]

$-0.6663$

[0.610]

0.0303

[0.521]

$-1.2266^{* *}$

[0.501]

$-0.7344$

[0.736]

$0.0022 * * *$
$[0.000]$
1,685
0.1760

$0.0022 * * *$

[0.000]

1,685

0.1940
Country-fixed effects

(4)

1.4895

$-0.4207$

[2.430]

0.0440

[0.167]

$-0.0157^{*}$

[0.009]

0.0052

[0.020]

$-0.0131$

[0.021]

$-0.1804 *$

[0.094]

$-0.0348^{*}$

[0.020]

0.1850

[0.608]

0.6453

[0.717]

0.3148

[0.547]

1.0074

[0.624]

$-0.7539$

[1.405]

$-0.0010$

[0.001]

1,685

0.351

* significant at $10 \% ; * *$ significant at $5 \% ; * * *$ significant at $1 \%$. Figures are Poisson panel regression results. An intercept term and country dummies are included, but not reported here. The coefficient of average precipitation in specifications (2) and (4) represents the coefficient for Southeast Asia- the reference subregion (omitted dummy). Robust country-cluster z statistics in brackets 
Table 4 Intense hydrometeorological and climatological disasters in Asia and the Pacific

Dependent variable: Frequency of intense hydrometeorological/climatological disasters, by decade (1971-2010)

\begin{tabular}{|c|c|c|c|c|}
\hline Explanatory variables & (1) & (2) & (3) & (4) \\
\hline & \multicolumn{2}{|c|}{ Hydrometeorological } & \multicolumn{2}{|c|}{ Climatological } \\
\hline \multicolumn{5}{|l|}{ Exposure } \\
\hline \multirow[t]{2}{*}{ Ln(population density) } & $0.1781 *$ & $0.2183^{* *}$ & -0.0060 & -0.0076 \\
\hline & {$[0.096]$} & {$[0.108]$} & {$[0.013]$} & {$[0.013]$} \\
\hline \multicolumn{5}{|l|}{ Vulnerability } \\
\hline \multirow[t]{2}{*}{ Ln(GDP per capita, constant $2000 \$)$} & $5.6830 * * *$ & $5.5177 * * *$ & -0.0293 & -0.0321 \\
\hline & {$[2.134]$} & {$[2.091]$} & {$[0.135]$} & {$[0.137]$} \\
\hline \multirow[t]{2}{*}{ Square of Ln(GDP per capita, constant $2000 \$)$} & $-0.3530 * * *$ & $-0.3422 * * *$ & 0.0015 & 0.0016 \\
\hline & {$[0.131]$} & {$[0.128]$} & [0.009] & [0.009] \\
\hline \multicolumn{5}{|l|}{ Climate } \\
\hline \multirow[t]{2}{*}{ Average precipitation deviation } & $0.0480 * *$ & & -0.0005 & \\
\hline & {$[0.024]$} & & {$[0.002]$} & \\
\hline \multirow[t]{2}{*}{ Average temperature anomalies } & & & $0.0718^{*}$ & \\
\hline & & & {$[0.039]$} & \\
\hline \multirow{2}{*}{$\begin{array}{l}\text { No. of years per decade that average precipitation deviation } \\
\text { exceeds 1961-1990 average }\end{array}$} & & $0.1280^{*}$ & & 0.0028 \\
\hline & & {$[0.069]$} & & {$[0.009]$} \\
\hline \multirow{2}{*}{$\begin{array}{l}\text { No. of years per decade with average temperature deviation } \\
\text { exceeds 1961-1990 average }\end{array}$} & & & & $0.0121 * * *$ \\
\hline & & & & {$[0.005]$} \\
\hline \multirow[t]{2}{*}{ Population (in million) } & $0.0091 * * *$ & $0.0090 * * *$ & $0.0008 * * *$ & $0.0008 * * *$ \\
\hline & {$[0.002]$} & {$[0.002]$} & {$[0.000]$} & {$[0.000]$} \\
\hline Observations & 156 & 156 & 156 & 156 \\
\hline R-squared & 0.5288 & 0.5297 & 0.5111 & 0.5137 \\
\hline No. of countries & 52 & 52 & 52 & 52 \\
\hline
\end{tabular}

* significant at $10 \%$;* significant at $5 \%$; *** significant at $1 \%$. Figures are results of negative binomial panel regression with random effects. An intercept term is included but not reported here. Robust statistics in brackets. Only 52economies with complete observations by decade were included in this decadal analysis. The Occupied Palestinian Territory was excluded in the analysis since it has incomplete observations across the 4 decades in 1971-2010

Climatic data are annualized to have a common frequency and hence balance across variables: all other variables used in our regression analysis, such as the number of disasters, GDP, population are available annually. We use climate anomalies rather than absolute climate values since the former would seem to allow for more meaningful comparisons across countries. For example, even if two countries have the same temperature in a month it is possible that for one country it is greater than the long term average and the opposite for the other. The IPCC also principally uses annual mean anomalies in their presentations. Alternative measures such as extremes of precipitation and temperature anomalies in a year may present some problems. For example, extreme precipitation anomaly in a dry season may not result in flooding. Aggregation of anomalies to the annual and country level, however, could smoothen some of the seasonal and geographical fluctuations. Further research on more granular temporal periods and spatial scales would be of interest conditional upon the necessary data being available. 
Table 5 Descriptive statistics (1971-2010)

\begin{tabular}{|c|c|c|c|c|c|}
\hline Variable & Obs. & Mean & $\begin{array}{l}\text { Std. } \\
\text { Dev. }\end{array}$ & Min. & Max. \\
\hline Frequency of intense hydrometeorological disasters & 1,685 & 1.11 & 2.48 & 0.00 & 25.00 \\
\hline Frequency of intense climatological disasters & 1,685 & 0.11 & 0.42 & 0.00 & 6.00 \\
\hline Population density (people per square km) & 1,685 & 622.62 & $2,171.06$ & 1.12 & $19,416.29$ \\
\hline Population (million) & 1,685 & 71.44 & 217.56 & 0.05 & $1,337.83$ \\
\hline GDP per capita (constant $2000 \$$ ) & 1,685 & $6,579.37$ & $9,707.36$ & 122.09 & $61,374.75$ \\
\hline $\begin{array}{l}\text { Average precipitation deviation ( } \mathrm{mm} / \text { month) } W_{i}^{t}=\sum_{1}^{n}\left(p_{s}^{t}-\bar{p}\right) \\
/ n \text {. where } p_{s}^{t} \text { represents the average precipitation in station } \\
s \text { in year } t \bar{p} \text { is the average precipitation for } 1960-1990 \text {, and } \\
n \text { is the total number of stations in country } i\end{array}$ & 1,685 & -0.77 & 14.88 & -95.44 & 74.88 \\
\hline East Asia & 1,685 & 0.09 & 5.67 & -39.44 & 46.96 \\
\hline South Asia & 1,685 & -0.04 & 3.85 & -29.48 & 26.23 \\
\hline Southeast Asia & 1,685 & 0.18 & 8.88 & -55.78 & 60.65 \\
\hline Central Asia & 1,685 & -0.13 & 2.55 & -14.05 & 12.96 \\
\hline Pacific & 1,685 & -0.86 & 9.43 & -95.44 & 74.88 \\
\hline $\begin{array}{l}\text { Average temperature anomalies } W_{i}^{t}=\sum_{1}^{n}\left(a_{s}^{t}-\vec{a}\right) / n \text {. where } a_{s}^{t} \\
\text { represents the average temperature in station } s \text { in year } t, \bar{a} \text { is } \\
\text { the average temperature for } 1960-1990 \text {, and } n \text { is the total } \\
\text { number of stations in country } i\end{array}$ & 1,685 & 0.32 & 0.50 & -1.42 & 2.41 \\
\hline East Asia & 1,685 & 0.04 & 0.22 & -1.02 & 2.41 \\
\hline South Asia & 1,685 & 0.05 & 0.23 & -1.17 & 1.74 \\
\hline Southeast Asia & 1,685 & 0.04 & 0.16 & -0.50 & 1.14 \\
\hline Central Asia & 1,685 & 0.16 & 0.43 & -1.42 & 2.22 \\
\hline Pacific & 1,685 & 0.03 & 0.12 & -0.60 & 1.19 \\
\hline
\end{tabular}

$\mathrm{GDP}=$ gross domestic product, Max. = maximum value, Min. $=$ minimum value, Obs. $=$ number of observations, $\mathrm{PPP}=$ purchasing power parity, Std. Dev.=standard deviation

Sources: Data on number of intense climate-related disasters based on natural disaster observations reported on Emergency Event Database (EM-DAT) Centre for Research on the Epidemiology of Disasters accessed 6 December 2011 (http://www.emdat.be); Population, Population Density, and GDP per capita are from the World Bank's World Development Indicators Online accessed 14 January 2012 (http://databank.worldbank. org); Average Precipitation Deviation is from Global Precipitation Climatology Center (GPCC 2011) accessed 28 December 2011 (http://www.gpcc.dwd.de); Average Temperature Anomalies is from Met Office Hadley Centre and the Climate Research Unit at the University of East Anglia accessed 28 December 2011 (http://www.cru.uea. ac.uk/cru/data/temperature)

It would also be useful to test our model using alternative exposure, vulnerability and climate variables, as well as continue extending the data series as far as possible. The work can also be extended to include other regions of world.

\section{Discussion}

The main purpose of this study is to discuss the major factors associated with the frequency of climate-related disasters observed in Asia-Pacific over recent decades. Taken together, the results of the econometric analysis suggest that three principal factors - rising population exposure, population vulnerability, and climate anomalies - play a part, even if notably differentiated amongst them and across subregions. While climatological disasters are strongly 
Table 6 Number of sample observations by economy and subregion*

\begin{tabular}{|c|c|c|c|c|c|c|}
\hline \multirow[t]{2}{*}{ Economy } & \multicolumn{5}{|c|}{ Number of Observations } & \multirow[t]{2}{*}{ Period } \\
\hline & $1971-80$ & $1981-90$ & $1991-2000$ & $2000-10$ & Total & \\
\hline \multicolumn{7}{|l|}{ East Asia } \\
\hline China, People's Rep. of & 10 & 10 & 10 & 10 & 40 & 1971-2010 \\
\hline Hong Kong, China & 10 & 10 & 10 & 10 & 40 & 1971-2010 \\
\hline Japan & 10 & 10 & 10 & 10 & 40 & 1971-2010 \\
\hline Korea, Rep. of & 10 & 10 & 10 & 10 & 40 & 1971-2010 \\
\hline Macao, China & - & 9 & 10 & 10 & 29 & $1982-2010$ \\
\hline Mongolia & - & 10 & 10 & 10 & 30 & 1981-2010 \\
\hline \multicolumn{7}{|l|}{ South Asia } \\
\hline Bangladesh & 10 & 10 & 10 & 10 & 40 & 1971-2010 \\
\hline Bhutan & 1 & 10 & 10 & 10 & 31 & 1980-2010 \\
\hline India & 10 & 10 & 10 & 10 & 40 & 1971-2010 \\
\hline Iran & 10 & 10 & 10 & 9 & 39 & 1971-2009 \\
\hline Nepal & 10 & 10 & 10 & 10 & 40 & 1971-2010 \\
\hline Pakistan & 10 & 10 & 10 & 10 & 40 & 1971-2010 \\
\hline Sri Lanka & 10 & 10 & 10 & 10 & 40 & 1971-2010 \\
\hline \multicolumn{7}{|l|}{ Southeast Asia } \\
\hline Brunei Darussalam & 7 & 10 & 10 & 10 & 37 & $1974-2010$ \\
\hline Cambodia & - & - & 8 & 10 & 18 & 1993-2010 \\
\hline Indonesia & 10 & 10 & 10 & 10 & 40 & 1971-2010 \\
\hline Lao PDR & - & 7 & 10 & 10 & 27 & 1984-2010 \\
\hline
\end{tabular}

associated with changing temperature, hydrometeorological disasters are most clearly associated with rising exposure of people as well as precipitation anomalies.

Results from this study suggest that precipitation and temperature anomalies are empirically relevant in explaining the threats from hazards of nature. Many policy makers are aware that atmospheric concentrations of $\mathrm{CO}_{2}$, the primary anthropogenic GHG, have recently surpassed $400 \mathrm{ppm}$ and are set to exceed $450 \mathrm{ppm}$ in less than a quarter of a century, given current increases of over $2 \mathrm{ppm}$ a year. IPCC's 5th Assessment Report affirms the human influence in the warming of the climate system, mostly through the increase in the atmospheric concentration of $\mathrm{CO}_{2}$, while this paper's econometric results suggest an association between climate change and greater frequency of intense disasters due to floods, storms, droughts and heat waves. These two results put together suggest an association between the frequency of intense climate-related disasters in Asia-Pacific and GHG emissions.

Two sets of policy implications follow. First, reducing exposure of the population and their vulnerability should feature centrally in policies to confront the growing threat from floods, storms, droughts and heat waves. Second, climate mitigation should be added as a crucial dimension in disaster prevention.

To sum up, this study finds that anthropogenic climate change is associated with the frequency of intense natural disasters in Asia-Pacific countries. A major implication of this is that, in addition to dealing with exposure and vulnerability, disaster prevention would benefit from addressing climate change through reducing man made greenhouse gases in the 
Table 6 (continued)

\begin{tabular}{|c|c|c|c|c|c|c|}
\hline \multirow[t]{2}{*}{ Economy } & \multicolumn{5}{|c|}{ Number of Observations } & \multirow[t]{2}{*}{ Period } \\
\hline & $1971-80$ & $1981-90$ & $1991-2000$ & $2000-10$ & Total & \\
\hline Malaysia & 10 & 10 & 10 & 10 & 40 & 1971-2010 \\
\hline Philippines & 10 & 10 & 10 & 10 & 40 & $1971-2010$ \\
\hline Singapore & 10 & 10 & 10 & 10 & 40 & 1971-2010 \\
\hline Thailand & 10 & 10 & 10 & 10 & 40 & $1971-2010$ \\
\hline Timor-Leste & - & - & 2 & 10 & 12 & 1999-2010 \\
\hline Viet Nam & - & 7 & 10 & 10 & 27 & 1984-2010 \\
\hline \multicolumn{7}{|l|}{ Central Asia } \\
\hline Armenia & - & 1 & 10 & 10 & 21 & 1990-2010 \\
\hline Azerbaijan & - & 1 & 10 & 10 & 21 & 1990-2010 \\
\hline Bahrain & 1 & 10 & 10 & 10 & 31 & 1980-2010 \\
\hline Cyprus & 6 & 10 & 10 & 10 & 36 & 1975-2010 \\
\hline Georgia & 10 & 10 & 10 & 10 & 40 & 1971-2010 \\
\hline Iraq & - & - & 4 & 10 & 14 & $1997-2010$ \\
\hline Israel & 10 & 10 & 10 & 10 & 40 & 1971-2010 \\
\hline Jordan & 6 & 10 & 10 & 10 & 36 & 1975-2010 \\
\hline Kazakhstan & - & 1 & 10 & 10 & 21 & 1990-2010 \\
\hline Kuwait & - & - & 6 & 10 & 16 & 1986-2010 \\
\hline Kyrgyzstan & - & 5 & 10 & 10 & 25 & 1986-2010 \\
\hline Lebanon & - & 3 & 10 & 10 & 23 & 1988-2010 \\
\hline State of Palestine & - & - & 7 & 5 & 12 & 1994-2005 \\
\hline Oman & 10 & 10 & 10 & 10 & 40 & 1971-2010 \\
\hline Qatar & - & - & 1 & 10 & 11 & 2000-2010 \\
\hline Saudi Arabia & 10 & 10 & 10 & 10 & 40 & 1971-2010 \\
\hline Syrian Arab Republic & 10 & 10 & 10 & 10 & 40 & 1971-2010 \\
\hline Tajikistan & - & 6 & 10 & 10 & 26 & 1986-2010 \\
\hline Turkmenistan & - & 4 & 10 & 10 & 24 & $1987-2010$ \\
\hline United Arab Emirates & 6 & 10 & 10 & 10 & 36 & 1975-2010 \\
\hline Uzbekistan & - & 4 & 10 & 10 & 24 & $1987-2010$ \\
\hline Yemen & - & 1 & 10 & 10 & 21 & $1990-2010$ \\
\hline \multicolumn{7}{|l|}{ Pacific } \\
\hline Australia & 10 & 10 & 10 & 10 & 40 & $1971-2010$ \\
\hline Fiji & 10 & 10 & 10 & 10 & 40 & 1971-2010 \\
\hline Kiribati & 10 & 10 & 10 & 10 & 40 & $1971-2010$ \\
\hline New Caledonia & 10 & 10 & 10 & - & 30 & 1971-2000 \\
\hline New Zealand & 4 & 10 & 10 & 10 & 34 & 1977-2010 \\
\hline Papua New Guinea & 10 & 10 & 10 & 10 & 40 & 1971-2010 \\
\hline Solomon Islands & - & 1 & 10 & 10 & 21 & 1990-2010 \\
\hline Vanuatu & 2 & 10 & 10 & 10 & 32 & 1979-2010 \\
\hline
\end{tabular}

*This follows the United Nation's (UN) geographical subregional groupings since most of the data used (except for the climate anomalies and frequency of disasters) are from UN agencies. '-'denotes missing observations 
atmosphere. Prevention of natural disasters, as compared to response, does not receive adequate policy attention because these are generally considered one off acts of nature rather than being influenced by climatic factors caused by human activities. By giving an empirical basis to the relationship between climate anomalies and frequency of disasters, this study draws attention to prevention, including climate mitigation.

Acknowledgments The basic structure of this paper is built on a recent ADB Economics Working Paper by Vinod Thomas, Jose Ramon G. Albert and Rosa T, Perez. The authors are grateful to the Centre for Research on the Epidemiology of Disasters and to the Manila Observatory for collaboration and data support; Ramon Lopez, Debarati Guha-Sapir, Geoffrey Ducanes, and P.V. Srinivasan for their inputs; Robert Brakenridge, Hina Choksy, Sam Fankhauser, Thomas Kansy, Philip Keefer, Kelly Levin, Tom McDermott, Eric Neumayer, Swenja Surminksi and John Ward for their suggestions; and Ken Chomitz, Walter Kolkma, Valerie Reppelin-Hill, Alan Rodger, Vankina B. Tulasidhar, and Tomoo Ueda for comments; and Ruth Francisco for valuable assistance.

\section{Appendix}

Open Access This article is distributed under the terms of the Creative Commons Attribution License which permits any use, distribution, and reproduction in any medium, provided the original author(s) and the source are credited.

\section{References}

Allison PD, Waterman RP (2002) Fixed-effects negative binomial regression models. Sociol Methodol 32:247-265

Bakkensen, LA (2013) Adaptation and natural disasters: Evidence from global tropical cyclone damages and fatalities. Yale University, 30 September. http://cbey.yale.edu/uploads/Environmental\%20Economics\% 20Seminar/Bakkensen_Cyclones.pdf

Baltagi BH (2008) Econometric Analysis of Panel Data. Wiley

Barr R, Fankhauser S, Hamilton K (2010) Adaptation investments: A resource allocation framework. Mitig Adapt Strategies Glob Chang 15:843-858

Birkmann J (2007) Risk and vulnerability indicators at different scales: Applicability, usefulness and policy implications. Environ Hazard 7:20-31

Bouwer LM (2011) Have disaster losses increased due to anthropogenic climate change? Bull Amer Meteor Soc 92:39-46

Brath A, Montanari A, Moretti G (2006) Assessing the effect on food frequency of land use change via hydrological simulation (with uncertainty). J Hydrol 324:141-153

Brooks N, Adger N, Kelly M (2005) The determinants of vulnerability and adaptive capacity at the national level and the implications for adaptation. Global Environ Chang 15:151-163

Coumou D, Rahmsdorf S (2012) A decade of weather extremes. Nat Clim Chang 2:91-496

Cutter S, Emrich C, Webb J, Morath D (2009) Social vulnerability to climate variability hazards: A review of the literature. Oxfam America Technical Report. http://adapt.oxfamamerica.org

EM-DAT (2011) The OFDA/CRED International Disaster Database www.emdat.be Université Catholique de Louvain, Brussels

Füssel HM, Klein RJT (2006) Climate change vulnerability assessments: An evolution of conceptual thinking. Clim Change 75:301-329

GPCC (2011) GPCC full data reanalysis version $6 \mathrm{ftp} / / \mathrm{ftp}-\mathrm{anon} . d w d . d e / p u b /$ data/gpcc/html/fulldata_v6_ download.html

Hallegatte S (2012) Economics: The rising costs of hurricanes. Nat Clim Chang 2:148-149

Hansen J, Sato M, Hansen J, Sato M (2012) Paleoclimate implications for human-made climate change. In: Berger A, Mesinger F, Sijacki D (eds) Climate Change. Springer, Vienna

Hausman JA, Taylor WE (1981) A generalized specification test. Econ Lett 8:239-245

Hinkel J (2011) Indicators of vulnerability and adaptive capacity: Towards a clarification of the science-policy interface. Global Environ Chang 21(1):198-208

Huber M, Knutti R (2012) Anthropogenic and natural warming inferred from changes in earth's energy nalance. Nature Geosci 5:31-36 
Hutanuwatr K, Bolin B, Pijawka D (2012) Vulnerability and disaster in Thailand: Scale, power, and collaboration in post-tsunami recovery. (In: Pfeifer K, Pfeifer N (eds.) Forces of nature and cultural responses)

IPCC (2007) Climate change 2007: Synthesis report (eds. Core Writing Team, Pachauri RK, Reisinger A). IPCC, Geneva

IPCC (2012) Special report on managing the risks of extreme events and disasters to advance climate change adaptation. Cambridge University Press, Cambridge

IPCC (2013) Climate change 2013: The physical science basis. Cambridge University Press, Cambridge

Kahn M (2005) The death toll from natural disasters: The role of income, geography and institutions. Rev Econ Stat 87:271-284

IPCC (2014) Climate Change 2014: Impacts, Adaptation, and Vulnerability. Part B: Regional Aspects. Contribution of Working Group II to the Fifth Assessment Report of the Intergovernmental Panel on Climate Change. Cambridge University Press, Cambridge and New York, USA

Kellenberg DK, Mobarak AM (2008) Does rising income increase or decrease damage risk from natural disasters? J Urban Econ 63:788-802

Kelly PM, Adger WN (2000) Theory and practice in assessing vulnerability of climate change and facilitating adaptation. Clim Chang 47(4):325-352

Knutson TR, McBride JL, Chan J, Emanuel K, Holland G, Landsea, Held I, Kossin J, Srivastava A, Sugi M (2010) Tropical cyclones and climate change. Nature Geosci 3:157-163. http://www.nature.com/ngeo/ journal/v3/n3/abs/ngeo 779.html

Kunkel KE, Karl TR, Brooks H, Kossin J, Lawrimore JH, Arndt D, Bosart L, Changnon D, Cutter SL, Doesken N, Emanuel K, Groisman KY, Katz RW, Knutson T, O’Brien J, Paciorek CJ, Peterson TC, Redmond K, Robinson D, Trapp J, Vose R, Weaver S, Wehner M, Wolter K, Wuebbles D (2013) Monitoring and understanding trends in extreme storms: State of knowledge. B Am Meteorol Soc 94:499-514

Li T, Horton RM, Kinney P (2013) Projections of seasonal patterns in temperature-related deaths for Manhattan, New York. Nat Clim Chang 3:717-721

Luers AL (2005) The surface of vulnerability: an analytical framework for examining environmental change. Global Environ Chang 15:214-223

McDowell G, Ford JD, Lehner B, Berrang-Ford L, Sherpa A (2013) Climate-related hydrological change and human vulnerability in remote mountain regions: a case study from Khumbu, Nepal. Reg Environ Chang 13(2):299-310

Mendelsohn R, Emanuel K, Chonabayashi S, Bakkensen L (2012) The impact of climate change on global tropical cyclone damage. Nat Clim Chang 2:205-209

Morice CP, Kennedy JJ, Rayner NA, Jones PD (2012) Quantifying uncertainties in global and regional temperature change using an ensemble of observational estimates: The HadCRUT4 dataset. J Geophys Res 117:D08101

Noy I (2009) The macroeconomic consequences of disasters. J Dev Econ 88:221-231

O'Brien K, Eriksen S, Nygaard LP, Schjolden A (2007) Why different interpretations of vulnerability matter in climate change discourses. Climate Policy 7(1):73-88

Peduzzi P, Dao H, Herold C, Mouton F (2009) Assessing global exposure and vulnerability towards natural hazards: the Disaster Risk Index. Nat Hazard Earth Sys Sci 9:1149-1159

Pielke RA Jr, Gratz J, Landsea CW, Collins D, Saunders M, Musulin R (2008) Normalized hurricane damage in the United States: 1900-2005. Nat Hazards Rev 9:1-29

Rentschler JE (2013) Why resilience matters: The poverty impacts of disasters. World Bank Policy Research Working Paper No. 6699 http://www-wds.worldbank.org/external/default/WDSContentServer/WDSP/IB/ 2013/11/12/000158349_20131112151733/Rendered/PDF/WPS6699.pdf

Rudolf, B., Becker, A., Schneider, U., Meyer-Christoffer, A. \& Ziese M (2010) GPCC Status Report. Global Precipitation Climatology Centre gpcc.dwd.de

Skidmore M, Toya H (2002) Do natural disasters promote long-run growth? Econ Inq 40(4):664-687

Smith B, Wandel J (2006) Adaptation, adaptive capacity and vulnerability. Global Environ Chang 16(3):282-292

Stott PA, Allen M, Christidis N, Dole R, Hoerling M, Huntingford C, Pall P, Perlwitz J, Stone D (2012) Attribution of weather and climate-related extreme events. WCRP Position Paper on ACE http://ibrary. wmo.int/pmb_ged/wcrp_2011-stott.pdf

Taubenböck H, Post J, Roth A, Zosseder K, Strunz G, Dech S (2008) Conceptual vulnerability and risk framework as outline to identify capabilities of remote sensing. Nat Hazard Earth Sys Sci 8:409-420. doi: 10.5194/nhess-8-409-2008

Thomalla F, Downing T, Spanger-Siegfried E, Han GY, Rockstrom J (2006) Reducing hazard vulnerability: Towards a common approach between disaster risk reduction and climate adaptation. Disasters 30(1):3948

Thomas V, Albert JRG, Perez RT (2013) Climate-related disasters in Asia and the Pacific. ADB Economics Working Paper Series No. 358. http://www.adb.org/publications/climate-related-disasters-asia-and-pacific 
Tol RSJ, Yohe GW (2007) The weakest link hypothesis for adaptive capacity: An empirical test. Global Environ Chang 17:218-227

Toya H, Skidmore M (2007) Economic development and the impacts of natural disasters. Econ Lett 94:20-25 Trenberth KE (2011) Changes in Precipitation with Climate Change. Climate Change Research 47:123-138

Turner BL II, Kasperson RE, Matsone PA, McCarthy JJ, Corell RW, Christensene L, Eckley N, Kasperson J, Luerse XA, Martello ML, Polskya C, Pulsiphera A, Schiller A (2003) A framework for vulnerability analysis in sustainability science. PNAS 100(14):8074-79 